\title{
Puerperal fever and neonatal pleural empyema and bacteremia caused by group A streptococcus
}

Laurance Lequier MD, Wendy L Vaudry MD FRCPC

\begin{abstract}
L Lequier, WL Vaudry. Puerperal fever and neonatal pleural empyema and bacteremia caused by group A streptococcus. Can J Infect Dis 1998;9(3):185-189.

A term neonate developed early onset of sepsis and pleural empyema with group A streptococcus. Her mother also became septic with group A streptococcus in the early postpartum period. The infant required initial chest tube drainage. After reaccumulation of pleural fluid after removal of the chest tube, a thoracotomy with decortication was performed. The isolates of group A streptococcus were analyzed and found to be identical serotypes of the same bacterium. The serotyping revealed both to be $\mathrm{M}$ type 1 , T pattern 1 . Polymerase chain reaction detected the genomic sequence for streptococcal pyrogenic exotoxin A and B in both isolates. With the increase in invasive streptococcal infections in the community, serious perinatal infections may become more frequent.
\end{abstract}

Key Words: Group A streptococcus, Neonates, Pleural empyema, Puerperal fever

Fièvre puerpérale, empyème pleural néonatal et bactériémie causés par des streptocoques du groupe A

RÉSUMÉ : Un bébé né à terme a rapidement développé une septicémie et un empyème pleural attribuables à des streptocoques du groupe A. Sa mère a aussi développé une septicémie au début de la période post-partum. Le nourrisson a nécessité un drainage thoracique initial. Après une nouvelle accumulation du liquide pleural faisant suite au retrait du drain , on a pratiqué une thoracotomie avec décortication. Les isolats des streptocoques du groupe A ont été analysés et sont apparus comme des sérotypes identiques de la même bactérie. Le typage sérologique a révélé à la fois une protéine $\mathrm{M}$ type 1 et une protéine $\mathrm{T}$ modèle 1 . L'amplification génique a décelé la séquence génomique pour les exotoxines pyrogènes streptococciques A et B dans les deux isolats. Avec l'augmentation des infections streptococciques invasives extra-hospitalières, l'incidence des infections périnatales graves pourrait augmenter.

A lthough group A streptococcus was previously a common cause of puerperal fever and neonatal infections, it is now an extremely unusual, serious pathogen in the perinatal period. It is certainly a rare cause of neonatal pleural empyema. We report the clinical and microbiological details of a mother who developed sepsis with group A streptococcus and her infant who also developed sepsis with group A streptococcus with the focus of infection being a pleural empyema.

\section{CASE PRESENTATION}

A female infant was born to a 17-year-old primigravid mother at 38 weeks gestation by spontaneous uncomplicated vaginal delivery. Membranes were ruptured artificially two hours before delivery, and some meconium staining of amniotic fluid was noted. The baby was healthy and vigorous at birth, weighing $2480 \mathrm{~g}$ with APGAR scores of 8 and 9 at 1 and 5 mins, respectively. Shortly after birth, she was noted to be 
pale and lethargic. Her physical examination was otherwise unremarkable. A septic work-up was completed, and she was started on intravenous ampicillin (100 mg/kg/day) and gentamicin $(2.5 \mathrm{mg} / \mathrm{kg}$ every $18 \mathrm{~h}$, based on therapeutic monitoring), and she improved over the next three days. The infant's blood culture grew group A streptococcus sensitive to penicillin, and cerebrospinal fluid and urine cultures were both sterile. The antibiotic therapy was changed to intravenous penicillin $(50,000 \mathrm{U} / \mathrm{kg} /$ day $)$ on day 3 . On day 5 the baby became tachypneic and mottled in colour. She had an increased oxygen requirement and decreased air entry audible on the right side of her chest. A chest roentgenogram revealed a large right-sided pleural effusion. The child was intubated and transferred to the authors' tertiary care centre.

There, a right-sided thoracostomy drain was placed. Examination of the pleural fluid revealed $4 \mathrm{~g} / \mathrm{L}$ of protein, $9800 \times 10^{6}$ white cells/L, with $80 \%$ polymorphonuclear leukocytes and $20 \%$ monocytes. Gram stain revealed Gram-positive cocci, but there was no growth on culture. The dose of penicillin was increased to $200,000 \mathrm{U} / \mathrm{kg} / \mathrm{day}$. Over the next four days, the baby improved clinically, the pleural effusion decreased and drainage from the chest tube ceased. The chest tube was therefore removed on day 9. By day 11 the pleural effusion had reaccumulated. On day 13 a right-sided empyema decortication was performed. The tissue revealed no organisms on Gram stain and was sterile on culture. Histology revealed the pleural space to be obliterated by a very active inflammatory response of granulation tissue consisting of numerous young capillary sprouts embedded in fibroblastic tissue with histiocytes, plasma cells and many polymorphonuclear leukocytes. These findings are compatible with a pyogenic empyema in the process of organization. The infant received intravenous penicillin (200,000 U/kg/day) for seven days postdecortication and then was treated for two weeks with oral penicillin V $(200,000$ $\mathrm{U} / \mathrm{kg} /$ day). She continued to do well after discharge.

The infant's mother had malaise and fever in the early postpartum period. She had no obvious focus of infection on examination nor did she develop a rash or hypotension. She was started empirically on intravenous cefazolin and metronidazole. Vaginal and blood cultures grew group A streptococcus sensitive to penicillin, and her previous antibiotics were discontinued in favor of intravenous ampicillin. By day 3 postpartum, she had been afebrile and asymptomatic for $48 \mathrm{~h}$, and the intravenous ampicillin was discontinued. She was discharged home on a seven-day course of oral amoxicillin. She remained well postdischarge.

The organisms isolated from both the mother and infant were further analyzed at the National Centre for Streptococcus, Edmonton, Alberta. Serotyping was performed according to traditional methodologies for $M$ typing (1), T typing (2) and production of opacity factor (3). Detection of the genetic sequences for streptococcal pyrogenic exotoxins A, B and C was performed by polymerase chain reaction (4). Serotyping of the group A streptococcus isolates revealed that both were M type 1 , T pattern 1 and serum opacity factor negative. Streptococcal pyrogenic exotoxins (SPE) A and B were detected in both isolates by the polymerase chain reaction.

\section{DISCUSSION}

Pleural empyema is usually secondary to a primary pulmonary infection (5). Most pediatric patients with empyema are less than two years of age; however, neonatal pleural empyema is rare $(6,7)$. The predominant pathogens isolated from children with pleural empyema are Haemophilus influenzae, Streptococcus pneumoniae, Staphylococcus aureus, Bacteroides species and other anaerobes (5-9). Group A streptococcus is a rare cause of pleural empyema in children, with only two cases described in a review of 227 children with parapneumonic effusions (7). Group A streptococcus causing neonatal pleural empyema is exceedingly rare, with only three previous case reports in the literature (10-12).

Our case represents the first report of neonatal pleural empyema caused by group A streptococcus where the organism was isolated from the blood of both mother and infant. In two of the previously reported cases $(10,11)$, the organism was isolated from pleural fluid but not from blood. The third case was reported as a complication of neonatal varicella (12), and group A streptococcus was isolated from blood culture only. As well, the organisms from our case were serotyped and found to be the same in both mother and infant. Another case has been reported previously where a mother and infant twins with sepsis all had group A streptococcus of the same type isolated from blood cultures (13). However, neither infant had pleural empyema.

Neonatal bacteremia and sepsis in the preantibiotic era was most commonly associated with group A beta hemolytic streptococci $(14,15)$. In the 50 years preceding the latter part of the 1980s, the incidence of severe infections with group A streptococcus (including bacteremia, puerperal sepsis and scarlet fever) and nonsuppurative sequelae (such as rheumatic fever) has decreased markedly (16). Potential explanations for this decline may relate to antimicrobial therapy, improved socioeconomic conditions and decreased virulence of the infecting organism $(17,18)$. When cases of neonatal infection or puerperal fever caused by group A streptococci did occur, they were often associated with nursery or postpartum ward outbreaks (19-25). As demonstrated in this case, puerperal fever caused by group A streptococcus is characterized by high fever in the early puerperium often without other symptoms or signs of disease (26). This absence of other findings may lead to delays in initiating therapy. The fact that the mother in this case was treated with intravenous antibiotics early likely prevented her from developing overt endometritis and more severe puerperal sepsis. Potential sources for vertical transmission of infection include the transplacental route or by aspiration of amniotic fluid or vaginal secretions. The aspiration route was likely the source in our patient, who had a respiratory focus of infection.

In recent years there has been a resurgence of disease caused by group A streptococcus. Many reports indicate particularly an increase in $M$ type 1 and 3 strains of group A streptococci (27-30). M protein is an antiphagocytic virulence factor (31). M type 1 strains are not the most prevalent in puerperal fever; however, they have been reported (28). M type 1 strains associated with group A streptococcal septicemia in 
children were shown to be opacity factor negative in one series as was found in this case (32). However, both opacity factor positive and negative strains of various $M$ serotypes have been associated with invasive disease. Previous studies have shown a predominance of SPE A- and SPE B-producing strains (particularly SPE B) in invasive Group A streptococcal infections in children $(12,32,33)$. There is no reported association between pleural empyema and any particular $\mathrm{M}$ type or exotoxin, other than the above predominant strains noted in invasive streptococcal infection in children. Approximately $30 \%$ of the isolates submitted to the National Centre for Streptococcus were $M$ type $1 \mathrm{~T}$ pattern 1 and of those tested for SPE, 96\% were both $\mathrm{A}$ and $\mathrm{B}$ positive.

It is interesting that cultures of fluid from the chest tube drain showed no growth. This may be due to the antibiotic therapy before thoracostomy, and studies have shown that many antibiotics achieve a good concentration in the pleural space (34). In previous reports of children with empyema, between $13 \%$ and $47 \%$ of pleural fluid cultures showed no growth $(4-9,35)$, and in one series the causative organism was isolated from blood culture in only $14 \%$ of cases (9).

In the present case reaccumulation of pleural fluid occurred after chest tube removal despite adequate antibiotics. The conservative approach may have been successful had pleural drainage been undertaken earlier; once the pleural effusion becomes organized into a 'pleural peel', effective drainage and treatment are more difficult (36-38). Although the infection

\section{REFERENCES}

1. Rotta J, Krause RM, Lancefield RC, Everly W, Lackland H. New approaches for the laboratory recognition of $M$ types of group A streptococci. J Exp Med 1971;134:1298-315.

2. Griffith F. The serological classification of Streptococcus pyogenes. J Hyg 1934;34:542-84.

3. Johnson DR, Kaplan EL. Microtechnique for serum opacity factor characterization of group A streptococci adaptable to the use of human sera. J Clin Microbiol 1988;26:2025-30.

4. Tyler SD, Johnson WM, Huang JC, et al. Streptococcal erythrogenic toxin genes: Detection by polyerase chain reaction and association with disease strains isolated in Canada from 1940 to 1991. J Clin Micro 1992;30:3127-31.

5. Brusch JL, Weinstein L. Pleural empyemas. In: Feigin RD, Cherry JD, eds. Paediatric Infectious Diseases, 3rd edn. Philadelphia: WB Saunders Co, 1992:1:315-20.

6. Bechamps GJ, Lynn HB, Wenzel JE. Empyema in children: Review of Mayo Clinic experience. Mayo Clin Proc 1970;45:43-50.

7. Freij BJ, Kusmiesz H, Nelson JD, McCracken GH. Parapneumonic effusions and empyema in hospitalized children: a retrospective review of 227 cases. Pediatr Infect Dis 1984;3:578-91.

8. Brook I. Microbiology of empyema in children and adolescents. Pediatrics 1990;85:722-6.

9. Fajardo JE, Chang MJ. Pleural empyema in children: a nationwide retrospective study. South Med J 1987;80:593-6.

10. Petersen S, Astrad K. Pleural empyema in a newborn infant. Acta Pediatr Scand 1976;65:527-8.

11. Nathavitharana KA, Watkinson M. Neonatal pleural empyema caused by group A streptococcus. Pediatr Infect Dis 1994;13:671-2.

12. Davies HD, Matlow A, Scriver SR, et al. Apparent lower rates of streptococcal toxic shock syndrome and lower mortality in children with invasive group A streptococcal infections compared with adults. Pediatr Infec Dis J 1994;13:49-56.

13. Newburg PI, Williams ML. Group A beta hemolytic streptococcal sepsis in mother and infant twins. J Pediatr 1975;87:453.

14. Dunham EC. Septicemia in the newborn. Am J Dis Child 1933;45:229-53. might have been managed successfully by placement of a second chest tube, there is some evidence that children with empyema treated with decortication defervesce more rapidly and have earlier hospital discharge than those having closed tube thoracostomy (36). It has been recommended that streptococcal empyemas be treated for seven to 14 days. We chose to empirically treat this baby for three weeks postdecortication.

Although group A streptococcus was once the most common cause of puerperal and neonatal sepsis, it has now become a rare cause of disease in the perinatal period. However, coincident with the rise in this incidence of serious group A streptococcal disease in the past few years, this organism may once again become the cause of serious peripartum infections exemplified by this case. The increased prevalence of the $M$ type 1 strain and its association with severe disease may change the spectrum of maternal and neonatal disease to more invasive infection such as pleural empyema, particularly in the neonate whose host defences are less adequate. In this higher risk group, as well as in all cases of pleural collection of purulent material, serious consideration must be given to early effective drainage of the pleural space to ensure a timely cure.

ACKNOWLEDGEMENTS: The authors thank the National Centre for Streptococcus, Provincial Laboratory of Public Health for Northern Alberta for identifying and analyzing the group A streptococcus in this case.

15. Wilson HD, Eichenwald HF. Sepsis neonatorum. Pediatr Clin North Am 1974;21:571-82.

16. Centers for Disease Control. Group A beta-hemolytic streptococcal bacteremia: Colorado, 1989. MMWR 1990;39:3-11.

17. Quinn RW. Epidemiology of group A streptococcal infections their changing frequency and severity. Yale J Biol Med 1982;55:265-70.

18. Kaplan E, Wannamaker L. Group A streptococcal infections. In: Feigin R, Cherry J, eds. Textbook of Pediatric Infectious Diseases. Philadelphia: WB Sauders Co, 1987:1312-22.

19. Langewisch WH. An epidemic of group A type 1 streptococcal infections in newborn infants. Pediatrics 1956;18:438-46.

20. Dillon HC Jr. Group A type 12 streptococcal infection in a newborn nursery. Am J Dis Child 1966;112:177-84.

21. Tancer ML, McManus JE, Belotti G. Group A, type 33, B-hemolytic streptococcal outbreak on a maternity and newborn service. Am J Obstet Gynecol 1969;103:1028-33.

22. Geil CC, Castle NW, Mortimer EA Jr. Group A streptococcal infections in newborn nurseries. Pediatrics 1970;46:849-54.

23. McCabe WR, Abrams AA. An outbreak of streptococcal puerperal sepsis. N Engl J Med 1965;272:615-8.

24. Gordon G, Dale BAS, Lochhead D. An outbreak of group A haemolytic streptococcal puerperal sepsis spread by common use of bidets. Br J Obstet Gynecol 1994;101:447-8.

25. Claesson BEB, Claesson ULE. An outbreak of endometritis in a maternity unit caused by spread of group A streptococci from a showerhead. J Hosp Infect 1985;6:304-11.

26. Silver RM, Heddleston LN, McGregor JA, Gibbs RS. Life-threatening puerperal infection due to group A streptococci. Obstet Gynecol 1992;79:894-5.

27. Schwartz B, Facklarn RR, Breiman RF. Changing epidemiology of Group A streptococcal infection in the USA. Lancet 1990;336:1167-71.

28. Gaworzewski E, Colman G. Changes in the pattern of infection caused by Streptococcus pyogenes. Epidemiol Infect 1988;100:257-69. 
29. Kaplan EL, Johnson DR, Cleary PP. Group A streptococcal serotypes isolated from patients and sibling contacts during the resurgence of rheumatic fever in the United States in the mid 1980's. J Infect Dis 1989;159:101-3.

30. Martin PR, Hoiby EA. Streptococcal serogroup A epidemic in Norway 1987-1988. Scand J Infect Dis 1990;22:421-9.

31. Lancefield RC. Current knowledge of type-specific $M$ antigens of group A streptococci. J Immunol 1962;89:307-13.

32. Wheeler M, Roe M, Kaplan E, Schlievert P, Todd J. Outbreak of group A streptococcus septicemia in children: clinical, epidemiologic and microbiologic correlates. JAMA 1991;266:533-7.

33. Belani K, Schlievert P, Kaplan E, Ferrieri P. Association of exotoxin-producing group A streptococci and severe disease in children. Pediatr Infect Dis J 1991;10:351-4.

34. Taryle DA, Good JT, Morgan EJ, Reller LB, Sahn SA. Antibiotic concentrations in human parapneumonic effusions. J Antimicrob Chemother 1981;1:171-7.

35. Hoff SJ, Neblett WW, Edwards KM, et al. Parapneumonic empyema in children: decortication hastens recovery in patients with severe pleural infections. Pediatr Infect Dis J 1991;10:194-9.

36. Foglia RP, Randolph J. Current indications for decortication in the treatment of empyema in children. J Pediatr Surg 1987;22:28-33.

37. Raffensperger JG, Luck SR, Shkolnik A. Mini-thoracotomy and chest tube insertion for children with empyema. Thorac Cardiovasc Surg 1982;84:497-504.

38. Mayo P, Saba SP, McElvein RB. Acute empyema in children treated by open thoracotomy and decortication. Am Thorac Surg 1982;34:401-7. 


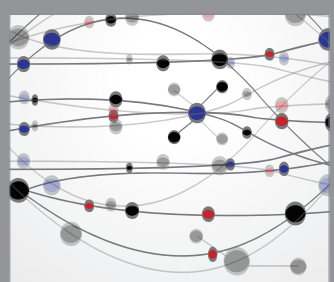

The Scientific World Journal
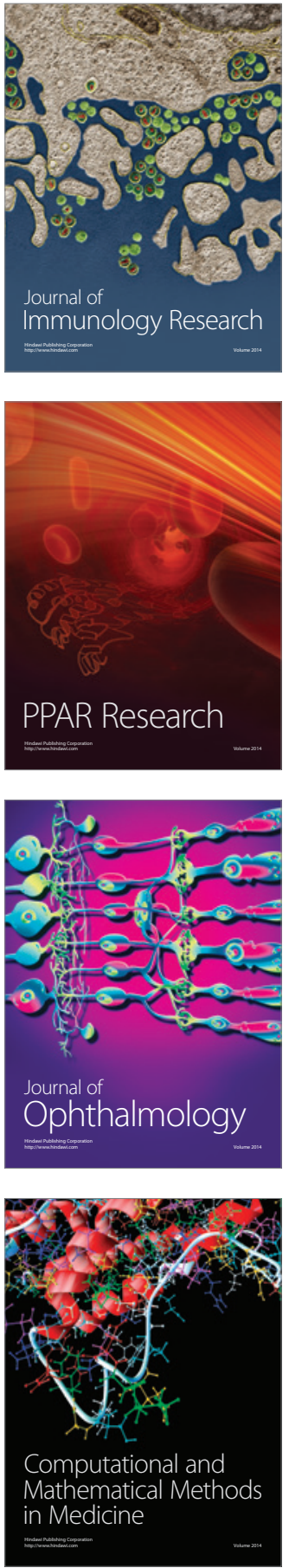

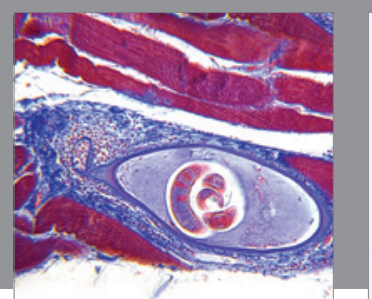

Gastroenterology Research and Practice

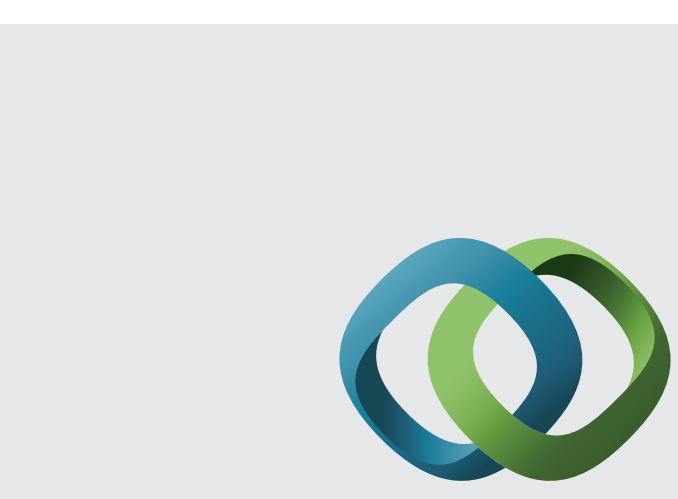

\section{Hindawi}

Submit your manuscripts at

http://www.hindawi.com
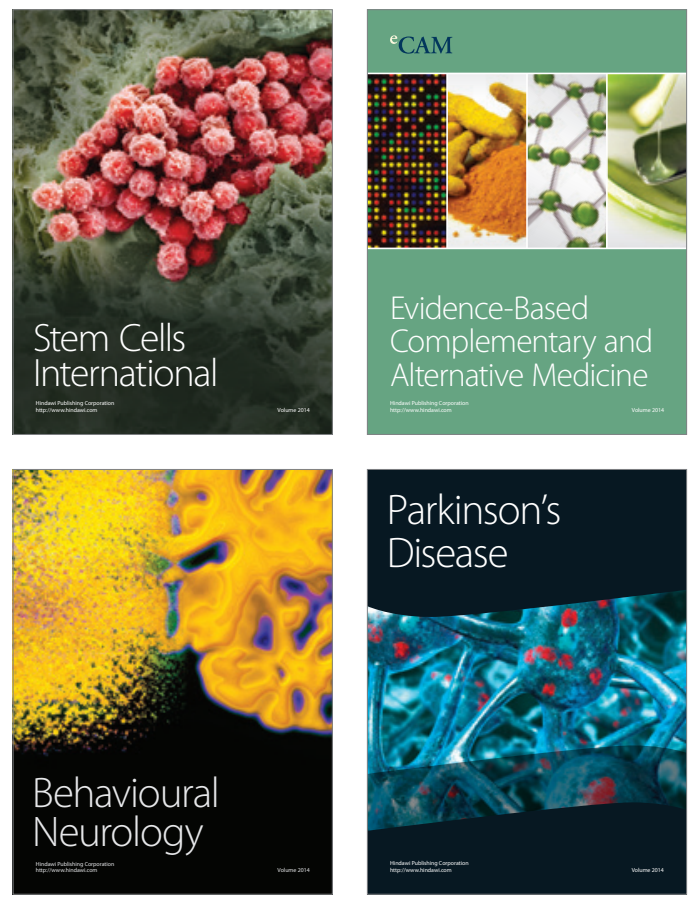
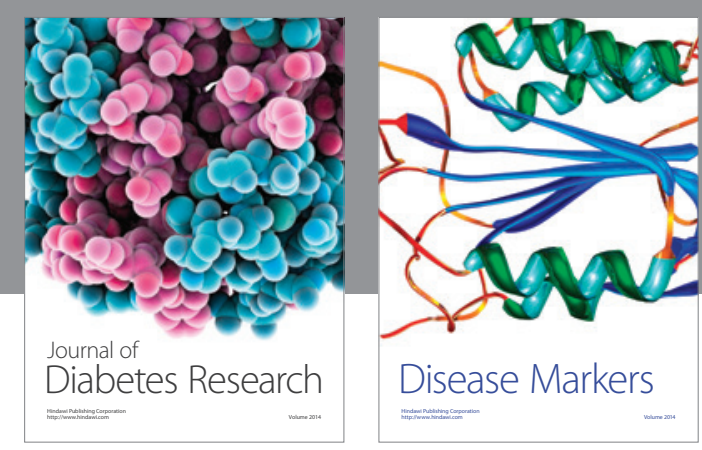

Disease Markers
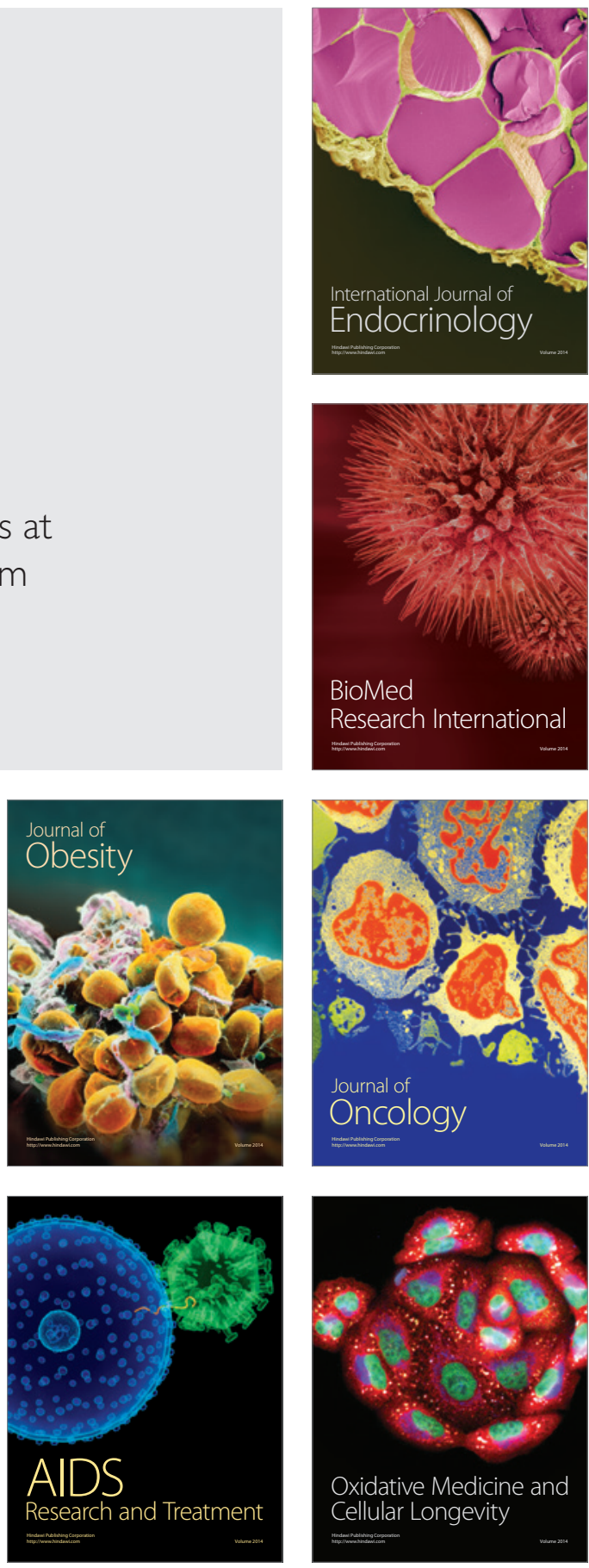